\title{
Workability of Safety Education and Training for Workers' Strategy in Accident Reduction in Selected Manufacturing Industries in Lagos State
}

\author{
Rachael B. Ayodele ${ }^{1, *} \&$ Martina A. Olubayo-Fatiregun ${ }^{1}$ \\ ${ }^{1}$ Department of Physical and Health Education, Obafemi Awolowo University, Ile- Ife, Nigeria \\ *Corresponding author: Department of Physical and Health Education, Obafemi Awolowo University, Ile- Ife, Nigeria. \\ Tel: 234-806-236-2125. E-mail: ayodeleebimbor@rocketmail.com
}

Received: August 27, 2012

Accepted: July 9, $2013 \quad$ Online Published: August 19, 2013

doi:10.5430/wje.v3n4p105

URL: http://dx.doi.org/10.5430/wje.v3n4p105

\begin{abstract}
This study determined the workability of Safety Education and Training for Workers' strategy in reducing accidents. A descriptive survey research design was used. A total of 20 Managerial staff with mean work experience of 13.5 years was selected from 10 manufacturing industries in Lagos State, using intact group method. They were $100 \%$ males. Data gathering tools were validated, self-developed questionnaire and accident data recorded in the industries, 12 months before and 12 months after the implementation of safety education and training for workers' programme. Data were treated using percentage and correlation analysis. Results indicated that the obtained $r=0.692$ is less than $r$ table (.707); df6 at .05 significance level, meaning that there is no significant positive relationship between pre-post intervention accident data in the industries. It was concluded that Safety Education and Training for Workers' strategy is not effective in reducing accidents in the industries. More researches and use of multiple safety programmes were suggested.
\end{abstract}

Keywords: workability; industries; workers; safety education; training strategy

\section{Introduction}

Hazards in the environment can be removed (eliminated); its probability can be reduced (containment) and the severity of its consequences can be reduced (Mitigation) (Amweelo, 2000). Many workplace Managements have achieved these three pertinent safety drivers culminating into relatively low or no-injury records. For instance, the Kinston North Carolina Plant of E.I. Dupont de Memours and Company, a textile fibre producer operated for more than nine and half years without a disabling or time-loosing injury and maintained 1st position in the American No-Injury reports for 31 years (American National Safety Council, 1993). Such low injury report was not achieved by magical explanations but had its credit to well-planned, well-organised and well-implemented hazard control programmes. Several of these programmes have been tested and their workability in reducing environmental hazards and accidents proven beyond doubt. Major of these hazard control strategies as outlined by Strasser, Aaron, Bohn and Eales (1973), Anderson (1976), Robertson and Raymond (1994) and Simon (2010) are: Education (area to which this study is delimited), Engineering control and Enforcement of safety rules and regulations, which they called the 3E's of accident control.

Though conventional, safety education and training for workers as a strategy had often been looked at as a positive approach to the prevention of accidents. Confirming the strength of education, Anderson (1976) said that it is one of the 3E's that lay in the heart of accident cause and eventually its control. Ekenedo (2010), Phillips (2010) and Sivaprakash and Sakthivel (2011) concurred that safety education is the proactive development of knowledge, attitude, behavior and skills for safe living. Bolarinwa (2002) felt that safety education and training for industrial workers are necessary, because he observed that the present level of awareness about occupational hazards among factory workers in rural areas of Nigeria was rather limited. According to the author, the subjects in his study were totally ignorant of the risks involved in their occupation and the necessary protective devices needed for safe production. There were facts that most industrial workers especially labourers were semi-illiterates (Afonja, 1975); young school leavers who lack education and training necessary for them to appreciate danger (Akpanokom, 1980). In line with these assertions, Amunega, (2002) found that the educational level of majority of the operators in the sawmill he investigated was below Senior Secondary School level. Such non-literate workers who usually fall in the manual tool handlers' group 
dominate the total industrial workforce (Osipov, 1991) and constitute the highest number of accident victims (Adams, 1994; Amweelo, 1992). In confirmation, Adams (1974) and Ayodele (2004) estimated that manual handling of goods was the source of $47.5 \%$ of industrial injuries. These situations suggest the need for proper education of workers.

The essence of health and safety education in industrial works or in any setting is sensitizing the society towards safe living and operations for hazard prevention. In his review, Bolarinwa (2002) stated that education for hazard control is the systematic development and cultivation of natural powers by instructing, training and example, the goal of which is hazard-free production. Odukogbe (1995) added that safety education in industries saves a lot of things ranging from human to material wastes, thus increasing the volume of production and quality of work. The scope of health and safety education in industries according to Nwajei (2002) and Onyoyo (2002) include; recognition and identification of hazards, evaluation of conditions of materials, accident costs and impact on overall development, control, eradication or avoidance of hazards.

Though widely accepted as a tool for accident prevention, controversies have generated regarding the efficacy of education in preventing accidents, especially when it is singly used. As revealed by Dixey (1999), some developing countries have questioned the workability of programmes aiming at making life easy, such as education and health services. While some researchers faulted the use of educational approach in accident prevention from the angle of poor implementation, others raised issues from the standpoint of the type of educational approaches used to create safety awareness. The authors noted that most educational programmes are not well implemented in terms of qualified personnel, safety facilities and equipment (Oboh \& Onohwakpor, 2002) and therefore, desired effects cannot be achieved (Suleiman \& Venkateswarlu, 2002). These authors were convinced that intervention programmes will achieve the desired effect, only if they are well implemented in terms of resources, training, monitoring and evaluation. Inadequacy of safety equipment, as found in industries (Eboh \& Onohwakpor, 2002) and universities (Ayodele, 2012) where these researchers conducted their studies could render safety education in the two settings ineffective. Not outrightly faulting education and training as measures of preventing accidents, Geetha and Ted (2009) said that such training is more effective in large firms but less effective in small firms. Michael, Sue, Kristin, Suzanne, Rommel and Gazi (2006) found that less engaging approaches to safety training like lectures and computer-based trainings yielded low result when compared to more engaging approaches like hand-on-trainings.

Earlier researchers like Bolarinwa (2002) and Nelly (2006) never disputed the fact that safety knowledge could be gained through educational programmes, but many of them seem not to agree that it will automatically cause a change in human behaviours. For instance, McLoughlin, Vince, Lee and Crawford (1982) and Nelly (2006) found that knowledge gains were shown in their respondents after being exposed to school health programme, but the incidence and severity of accidents were not reduced by either general campaign or the school health education programme. In line with these findings, Smith (1984) and Campbell, Hunter, Gemming and Stewart (1984) categorically stated that attempts at changing human behaviours through the usual Health Education approach as a way of injury control have shown transient or no effect, while some effects have even been shown to be harmful. For example, the authors found that drivers' education actually increased motor vehicle injury rate among teenagers by encouraging them to obtain their driving licenses early. Schlesinger, Dickson, Westaby, Lowen, Logrillo and Maiwald (1997)) also found no consistent differences in the trends in accident rates when a controlled study of health education in accident prevention was undertaken. There are indications therefore to suggest that knowledge is necessary but not a significant factor in changing behaviours.

Apart from poor implementation of safety programmes and problem of approach, McLoughlin, et. al. (1982) reasoned that the failure of educational programmes especially mass media to achieve low accident records could be due to one of attenuation of effects and multiplicity of message. Also, lack of permanency of the knowledge acquired during campaign or other educational programmes is often threatened. Bolarinwa (1993) also said that, it is not an easy job to get health messages across to individual employees who have overworked and sometimes pre-occupied by economic problems. Such situation could affect retention of information, thereby resulting in inability to put such knowledge into practice.

The concern of this study was to determine whether or not safety education and training for workers strategy as implemented in industries will yield a significant reduction in accident frequency and examine the factors that are likely to affect the workability of the strategy in accident reduction. It is hoped that the study would provide a common theoretical framework upon, which practical safety in industries can be based and highlight other strategies that could be combined with education to make it effective in accident prevention. It could further strengthen the existing relationship between education and industries and serve as a guide in safety programme design and evaluation in the industries concerned. 


\section{Statement of the Problem}

Many foreign-based researchers like Smith (1984), Campbell et.al. (1984), Bolarinwa (1993), Schlesinger, Dickson, Westaby, Lowen, Logrillo and Maiwald (1997)) and Nelly (2006) have found out that educational approach, which had often been looked at as an intervention strategy in many health problems yielded either transient or no effect in accident reduction especially when singly applied. The general and specific factors threatening the workability of education in accident prevention in Nigerian industries need to be examined, hence, this study. The specific objectives of the study are to examine how adequately industries implemented safety education and training for workers' strategy with regards to programme objectives, content, funding, personnel, facilities and equipment and evaluation, determine the effectiveness of safety education and training for workers strategy in preventing industrial accidents; and examine factors threatening the workability of educational approach in accident prevention.

\subsection{Research Hypotheses}

The only hypotheses which guided the conduct of this study states that: Safety Education and training for workers strategy will not significantly reduce accident frequency in industries.

\section{Methodology}

\subsection{Research Design}

The study used descriptive survey design.

\subsection{Sample and Sampling Technique}

Participants in the study were drawn using multi-stage sampling. All the existing industries in Lagos State were stratified into 10 sectoral groups as identified by the Manufacturing Association of Nigeria (1999). From each group, one industry was randomly selected totaling 10 industries. A total of 20 Managerial staff comprising $10(50 \%)$ Heads of accident control units or other similar departments and 10 (50\%) data processors/record keepers or other officers holding similar post, whose ages ranged between 32 and 63 years, took part in the study. They were $100 \%$ males and their mean work experience was 13.5 years.

\subsection{Instruments}

A combination of a validated, self-developed questionnaire and accident documents was used for data gathering.

\subsubsection{Questionnaire}

The 2-item questionnaire was based on the adequacy of programme implementation in the industries being investigated and factors that could render safety education and training ineffective in reducing industrial accidents.

\subsubsection{Documents}

Retrospective data of accident cases recorded twelve months before and 12 months after the commencement of safety education/training programme' implementation in industries were collected with the consent of the Industrial Managements.

\section{Results}

There were two sets of data. Data collected with the use questionnaire were analysed using simple percentage while the retrospective pre and post intervention accident data from each industry were compared using Pearson Product Moment Correlation Coefficient analysis. Results are as follows:

\subsection{Results on Implementation of Safety Education and Workers Training programmes in Industries}

A total of $16(80 \%)$ out of 20 managerial staff used in this study said that their industries have implemented safety education and training for workers strategy, while the remaining $4(20 \%)$ said that their industries have not. This indicated that $8(80 \%)$ out of 10 industries investigated have officially operated the safety education and training for workers strategy while the remaining $2(20 \%)$ industries have not officially mounted the programme. The data analysis was therefore based on 16 being total number of respondents from the eight industries, which have mounted the programme. 
Table 1: Percentage Distribution of Responses on the Implementation of Safety Education and Training for Workers Strategy in the Industries

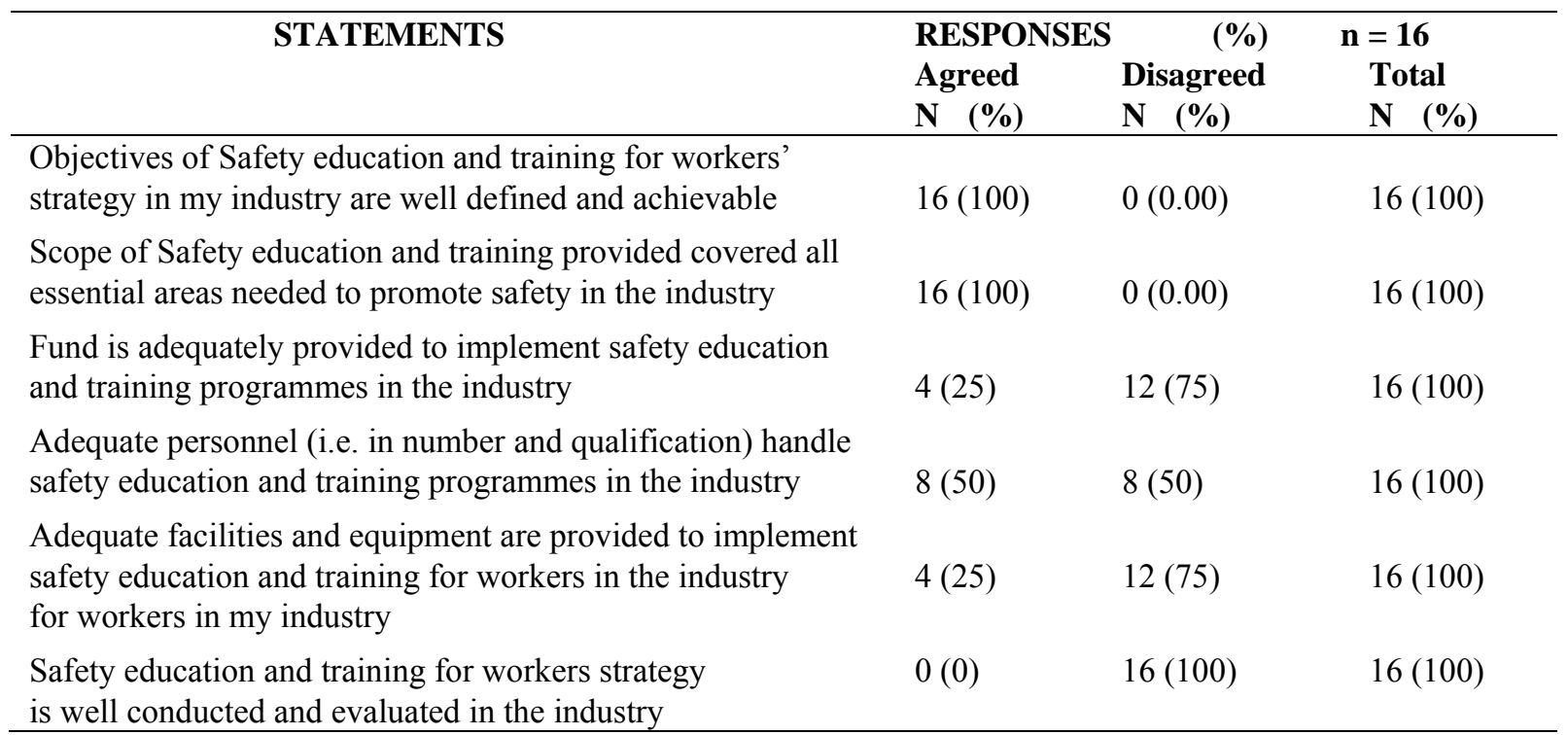

As shown in table 1 All the $16(100 \%)$ respondents whose industries have implemented safety education and training for workers' strategy agreed that the objectives of the programme are well defined and obtainable but as many as 12 $(75 \%)$ respondents disagreed that enough fund was provided to implement the strategy while only $4(25 \%)$ respondents agreed. As regards the adequacy of accident control personnel in industries, responses for and against were 50/50. While, as many as $12(75 \%)$ of the 16 respondents whose industries have implemented safety education and training for workers strategy disagreed with the statement that facilities and equipment were available to implement the programme, only $4(25 \%)$ respondents agreed. All the $16(100 \%)$ respondents claimed that safety education/workers' training programme was neither regularly conducted nor evaluated.

Table 2: Percentage Distribution of Responses on Factors Predicting Ineffectiveness of Safety Education/Training in Accident Prevention

\begin{tabular}{|c|c|c|c|}
\hline FACTORS RESPONSES & RESPO & TSES (\%) & $\mathbf{n}=16$ \\
\hline & Scores & Percentage & Ranking \\
\hline Safety education contents are not relevant to workers' needs & 105 & 72.9 & 4th \\
\hline Exposure of only a few workers to safety Education and trainings & 135 & 93.8 & 1 st \\
\hline Under-exposure of field workers to safety education and trainings & 132 & 91.7 & 2nd \\
\hline $\begin{array}{l}\text { Unavailability of facilities and equipment to accomplish knowledge } \\
\text { application }\end{array}$ & 122 & 84.7 & $3 \mathrm{rd}$ \\
\hline Wrong application of acquired knowledge & 67 & 46.5 & 6th \\
\hline Multiplicity of message & 70 & 48.6 & 5 th \\
\hline $\begin{array}{l}\text { Irregular safety training programmes leading to poor retention of safety } \\
\text { information }\end{array}$ & 52 & 36.1 & 7 th \\
\hline Deliberate failure of trained workers to apply their safety knowledge & 29 & 20.1 & 9th \\
\hline Failure of workers to attend safety education and trainings & 47 & 32.6 & 8th \\
\hline
\end{tabular}

Data in table 3 indicated that exposure of only a few workers: 135 (93.8\%) and non-involvement of field workers: 132 (91.7\%) to safety education/trainings and inadequate facilities and equipment to accomplish knowledge application: $122(84.7 \%)$ were ranked 1st, 2nd and 3rd major factors threatening the workability of safety education/workers' training in accident reduction. Failure of workers to attend safety education/workers' training programmes: 47 (32.6\%) and deliberate failure of the trained to apply safety knowledge gained during trainings were ranked 8th and 9th factors rendering the strategy ineffective. 


\subsection{Hypothesis Testing}

Safety Education and training for workers' strategy will not reduce accident frequency in industries. Data shown in table 3 depict the correlation analysis of accident data recorded before and after intervention.

Table 3: Correlation Analysis on Effects of Safety Education and Training for Workers' Strategy on Accident Reduction

\begin{tabular}{|c|c|c|c|c|c|}
\hline \multirow[t]{2}{*}{ Industries } & \multirow{2}{*}{$\begin{array}{c}\begin{array}{c}\text { Cases Before } \\
\text { Programme }\end{array} \\
x \\
\end{array}$} & \multicolumn{2}{|c|}{$\begin{array}{l}\text { Cases After } \\
\text { Programme }\end{array}$} & \multirow[b]{2}{*}{$y^{2}$} & \multirow[b]{2}{*}{$x y$} \\
\hline & & $y$ & $x^{2}$ & & \\
\hline A & 7 & 0 & 49 & 0 & 0 \\
\hline B & 3 & 5 & 9 & 25 & 15 \\
\hline $\mathrm{C}$ & 12 & 7 & 144 & 49 & 84 \\
\hline $\mathrm{D}$ & 6 & 1 & 36 & 1 & 6 \\
\hline $\mathrm{E}$ & 18 & 17 & 324 & 289 & 306 \\
\hline $\mathrm{F}$ & 9 & 1 & 81 & 1 & 9 \\
\hline G & 5 & 0 & 25 & 0 & 0 \\
\hline \multirow[t]{2}{*}{$\mathrm{H}$} & 1 & 6 & 1 & 36 & 6 \\
\hline & $\sum x=62$ & $\sum x=36$ & $\sum x^{2}=669$ & $\sum \boldsymbol{y}^{2}=401$ & $\sum x=426$ \\
\hline
\end{tabular}

Since obtained $r=0.692$ is less than $r$ table (.707) df6 at .05 significance level, it means there is no significant positive relationship between pre-post intervention accident data recorded in the industries. Therefore, safety education and training for workers is not effective in the industries.

\subsection{Discussion of Findings}

There are strong indications from this study that safety education and training for workers' strategy could not single-handedly yield reduction in accident frequency. This result was earlier found by McLoughlin et al (1982); Campbell et al. (1984); Smith (1984); Schlesinger, Dickson, Westaby, Lowen, Logrillo \& Maiwald (1997)) and Nelly (2006) who established knowledge gain, but did not find significant reduction in either the incidence or fatality of accidents following their subjects' exposure to Health Education. This result was however, contrary to the submission of Strasser et al. (1973). The results of this study, which indicated that safety education/training for workers' programmes were not well funded in the industries pointed to a major threat to its workability, because, Suleiman and Venkateswarfu (2002) had earlier stressed that intervention programmes will achieve the desired effect only if they are well implemented in terms of resources, training, monitoring and evaluation. Unfortunately, the song of average Nigerians is "No money". A 100\% of firms in Nigeria even those operated by the Governments complain of inadequate funding. The big question is, if the money is available to adequately implement any accident control strategy, are the present day Nigerian personnel assigned to implement such programmes not anxiously waiting to embezzle $80 \%$ of the fund and manage the remaining $20 \%$ for the projects? This singular factor could not have made the implementation of such accident control programmes viable in Nigerian industries. Also, this current study did not support the submission of Geetha \& Ted (2009) that safety training is more effective in large firms, because a $90 \%$ of manufacturing industries used in this study are large firms and yet, training was not found effective.

Exposure of only few workers to safety education/trainings and inadequate provision of facilities and equipment to accomplish knowledge application, found in this study to be major factors threatening the effectiveness of educational programme in accident prevention are still products of poor funding. If a programme is well funded, greater opportunities will be given to more workers to participate. The views of McLoughin, et. al. (1982) that multiplicity of message provided during safety education/training programmes accounted for the failure of educational approach in accident reduction was supported by the results of this study. For instance, when too many information are provided in a single training and especially when workers have overworked or are pre-occupied by economic problems (Bolarinwa, 1993), there is the tendency that most information will not be retained, especially if such trainings are not regularly given. When permanency of knowledge acquired during trainings is threatened, there is the likelihood that its applicability will also be threatened. 


\section{Conclusions}

From the results of this study, it is concluded that though, safety education and training for workers strategy objectives and contents were said to be adequate in most of the industries investigated, the strategy was not well-implemented in terms of provision of adequate fund, personnel, facilities and equipment. Safety education and training for workers alone was found to be ineffective in reducing accident frequency.

\section{Recommendations}

In order to make safety education and training for workers an effective accident intervention, the following recommendations were made:

- Respective industrial management must make adequate provision for fund, personnel, safety facility and equipment.

- The scope of School Health Education curriculum should be widened to cover the area of occupational health in order to provide opportunities for University graduates. Such occupational health education could help their knowledge application when they are eventually given appointments in industries.

- Industrial workers especially those in the production units should be given opportunities to participate in regular safety trainings, workshops, seminar and lectures to sharpen their awareness on safety precautions.

- Industrial managements should consider the use of multiple safety programmes at a time. A combination of public educational safety campaign and economic incentives is suggested.

- Given the fact that the data used for this study was derived barely a year after the mounting of the programme, the researcher hopes strongly that there might have been some improvement overyears, therefore, it is recommended that further studies spanning decade after the establishment of safety education in the industries under study should be conducted.

\section{References}

Adams, N. L. (1974). Using injury statistics to set safety goals. Personnel Practice Bulletin, 30(3), 244-256.

Afonja, S. A. (1976). Foundation of industrial accident causation. Safeguard, 14(1), 27-28

Ajala, J. A. (2000). Health and Safety Education in industry. Nigerian Journal of Health Education and Welfare of Special People, 4(1 \& 2), 63-72.

Akpanokom, I. P. (1980). Accident prevention and industrial safety. Trainers' Manual for Supervisors. Lagos: Center for Management Development. Pp. 52-62

American National Safety Council (1993). Industrial Accident Safety Data (1940-1970).

Amunega S. B. (2002). Occupational hazards in Odo-Okun sawmill in Ilorin West Local Government Area of Kwara State: Causes and prevention. Nigerian School Health Journal, $14(1 \& 2), 25-33$.

Amweelo, M. (1992). Accident prevention in Namibia. African Newsletter on Occupational Health and Safety, 2(2), 62.

Anderson, C. L. (1976). Health principles and practice. (Revised edition) New York. McGraw-Hill Company. Pp. 320-331

Bolarinwa, R. O. (2002). Generation and control of dust in local flour mills in Ilesa West and East Local Government Areas of Osun State. Journal of Physical Education and Research, VII(1), 821-824.

Campbell, B. J., Hunter, W. W., Gemming, M. C., \& Stewart, J. R. (1984). The Use of economic incentives and Public Education to increase seat belt use in a community. University of North Carolina Highway Safety Research Center. Pp. 98

Dixey, R. A. (1999). 'Fatalism' accident causation and prevention: Issues for health promotion from explanatory study in a Yoruba town, Nigeria. Health Education Research, 14(2), 197-208. http://dx.doi.org/10.1093/her/14.2.197

Eboh, L.O., \& Onohwakpor, A. E. O. (2002). Occupational health hazards and safety measures in Delta Glass PLC. Ughelli, Delta State. Nigerian School Health Journal, 14(1\&2), 95-104.

Ekenedo, G. O. (2010). Comprehensive First Aid and Safety for everyone at home, at work, at leisure. Port Harcourt, 
Rivers State. The Glory of the Latter House Publishing coy. Pp. $1-6$

Geetha, M. W., \& Ted, R. M. (2009). Does safety training reduce work injury in the U.S? The Ergonomics Open Journal, 2, 26-39. http://dx.doi.org/10.2174/1875934300902010026

McLoughlin, E., Vince., C. J., Lee, A. M., \& Crawford, J. D. (1982). Burn prevention: outcomes and implications. American Journal of Pubic Health, 72(3), 241-247. http://dx.doi.org/10.2105/AJPH.72.3.241

Michael, J. B., Sue, A. S., Kristin, S., Suzanne, C., Rommel, O. S., \& Gazi, I. (2006). Relative effectiveness of worker safety and health training methods. American Journal of Public Health, 96(2), 315-324. http://dx.doi.org/10.2105/AJPH.2004.059840

Nwajei, S. D., \& Nwanchukwu, A. E. (2002). Health and Safety Education as essential strategy in prevention of industrial hazards. Nigerian School Health Journal, 14(1\& 2), 157-165.

Nelly, J. S. (2006). Safety and Education: A handbook on School Health. Pp. 16 - 18

Odukogbe, O. A. (1995). Safety Regulations in Nigerite PLC. Unpublished paper presented at the seminar organized for Nigerite Industry PLC.

Onyoyo, H. A. (2002). Proactive strategies in occupational accident prevention in Kenya. African Newsletter on Occupational Health and safety, 2(2), 8-12.

Osipov, G. N. (1991). Industry and Labour in the U.S.S.R. The Social Science Paperback Edition. Tawistock Publications. Pp. 262.

Phillips, A. O. (2010). Concept of safety. In Safety Education, Ikulayo, P. B. (ed.). Ibadan. Olu-Akin Publishers. Pp. 19-27.

Robertson, C., \& Redmond, A. D. (1994). The management of major trauma(2nde ed.). Oxford: Oxford University Press, p5-16.

Schlesinger, E. R., Dickson, D. G., Westaby, J., Lown, L., Logrillo, V. M., \& Maiwald, A. A. (1997). A controlled study of health education in accident prevention: The Rockland Count Child Injury Project-1966. Injury Prevention, 3(3), 218 - 223. http://dx.doi.org/10.1136/ip.3.3.218

Simon, P. P. (2010). Developing an integral approach to system safety engineering. Engineering Management Journal, 22(2), 56-57.

Sivaprakash, P., \& Sakthivel, M. (2011). Discussion on accidents, hazards and risks in industries - A review. European Journal of Scientific Research, 52(1), 38-43.

Smith, G. S. (1984). Unintentional injuries: Intervention strategies and their potential for reducing human losses. A Position paper for the Carter Centre, Emory University, Atlanta Georgia. 113.

Strasser, M. K., Aaron, J. E., Bohn, R. C., \& Eales, J. R. (1973). Fundamentals of Safety Education(2nd edition.) New York. Macmillan Publishing Co. Inc. Pp. 296-313.

Suleiman, M. A., \& Venkateswarlu, K. (2002). A blueprint of effective Programmes to reduce health risk behaviour of adolescents. Journal of Nigerian Association of Women in Sports, 2(1), 38-42. 